\title{
SYSTEMIC ADMINISTRATION OF MK-801 PROTECTS AGAINST $N$-METHYL-D-ASPARTATE- AND QUISQUALATE-MEDIATED NEUROTOXICITY IN PERINATAL RATS
}

\author{
J. W. McDonald, ${ }^{*}$ F. S. Silverstein, $\uparrow+$ D. Cardona, $\$$ C. Hudson, $\$$

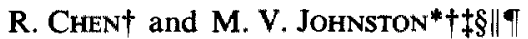

*Neuroscience Training Program and Departments of †Pediatrics and $\ddagger$ Neurology, Medical School, and $\$$ Center for Human Growth and Development, University of Michigan, Ann Arbor, MI 48104, U.S.A. IDepartments of Neurology and Pediatrics, Johns Hopkins University School of Medicine and the Kennedy Institute, Baltimore, MD 21205, U.S.A.

\begin{abstract}
Abstruct-MK-801, a non-competitive antagonist of $N$-methyl-Duaspartate-type glutamate receptors, was tested for its ability to antagonize excitotoxic actions of $N$-methyl-D-aspartate or quisqualic acid injected into the brains of seven-day-old rats. Stereotaxic injection of $N$-methyl-D-aspartate $(25 \mathrm{nmol} / 0.5 \mu \mathrm{l})$ or quisqualic acid $(100 \mathrm{nmol} / 1.0 \mu \mathrm{l})$ into the corpus striatum under ether anesthesia consistently produced severe unilateral neuronal necrosis in the basal ganglia, dorsal hippocampus and overlying neocortex. The distribution of the damage corresponded to the topography of glutamate receptors in the vulnerable regions demonstrated by previous autoradiographic studies. $N$-Methyl-D-aspartate produced severe, confuent neuronal destruction while quisqualic acid typically caused more selective neuronal necrosis. Intraperitoneal administration of $\mathrm{MK}-801(0.1-1.0 \mathrm{mg} / \mathrm{kg}) 30 \mathrm{~min}$ before $N$-methyl-D-aspartate injection had a prominent dose-dependent neuroprotective effects as assessed morphometrically by comparison of bilateral striatal, hippocampal and cerebral hemisphere cross-sectional areas five days later. A $1 \mathrm{mg} / \mathrm{kg}$ dose of MK-801 given as pre-treatment completely protected the infant brain. The same dose of MK-801 was also completely protective when administered 30 or $40 \mathrm{~min}$ after $N$-methyl-D-aspartate and afforded partial protection when given $2 \mathrm{~h}$ later. MK-801 pre-treatment also prevented the electrically confirmed behavioral seizures induced by $N$-methyl-D-aspartate. The drug significantly reduced striatal but not hippocampal or neocortical injury when given as two doses $(1 \mathrm{mg} / \mathrm{kg}) 30 \mathrm{~min}$ prior to and immediately following quisqualic acid injection.

The data indicate that systemic administration of MK-801 can prevent $N$-methyl-D-aspartate-induced neuronal injury in perinatal rat brain even when administered after the initial insult. MK-801 also partially antagonized quisqualic acid-mediated neurotoxicity, suggesting that quisqualic acid-induced toxicity is, in part, mediated through $N$-methyl-1)-aspartate receptor activation. The sensitivity of the developing brain to the toxicity of $N$-methyl-D-aspartate provides a sensitive and reproducible in viwo model for exploring these issues and for screening prospective neuroprotective drugs that act at the $N$-methyl-Daspartate receptor channel complex.
\end{abstract}

The excitatory amino acid (EAA) receptor subtypes, specific for $N$-methyl-D-aspartate (NMDA), quisqualate and kainate are uniquely distributed in the developing and mature brain and are distinguished by biochemical, ${ }^{15,24,25}$ electrophysiological ${ }^{1,60,35,53}$ and pharmacological criteria. ${ }^{8,18,19,37}$ Each of the receptor subtypes may mediate physiologic excitatory neuronal responses but under conditions of excessive receptor activation, agonists for these receptors are capable of initiating a cascade of events resulting in neuronal death in both the adult ${ }^{39,42.50}$ and immature brain. ${ }^{73.46 .49}$ The NMDA-preferring receptor subtype has been best characterized electrophysiologically

ๆTo whom correspondence should be addressed.

Abbreviations: APH, 7-aminophosphonoheptanoic acid; EAA, excitatory amino acid; EEG, electroencepha* logram; MK-801, \{(+)-5-methyl-10,11-dihydro-5H-dibenzo[a,d]cyclohepten-5,10-imine meleate \}; NMDA, $N$-methyl-D-aspartate; PBF, phosphate-buffered forma* lin; PBS, phosphate-buffered saline. and biochemically (for review see Ref. 8). NMDA activates a calcium-permeable cationic channel ${ }^{26}$ that is gated by $\mathrm{Mg}^{2+30,40}$ in a voltage-dependent manner. 11,27 The NMDA response is enhanced by glycine ${ }^{22}$ and is non-competitively blocked in a usedependent manner by phencyclidine receptor ligands including $\{(+)-5$-methyl-10,11-dihydro-5H-dibenzo$[a, d]$ cyclohepten-5,10-imine meleate $\}(\mathrm{MK}-801)^{6}$ and the dissociative anesthetic class of compounds. 29,54 Furthermore, the distributions of NMDA and phencyclidine receptors in the mammalian forebrain are identical. ${ }^{28}$ This finding, taken together with pharmacological evidence of interactions between these two receptor sites, suggests that NMDA and phencyclidine receptors may be components of the same receptor-ion channel complex.

Excessive NMDA receptor activation has been implicated in neuronal damage resulting from hypoxia-ischemia; ${ }^{31.36,45,47}$ hypoglycemia ${ }^{53}$ and sustained seizures. ${ }^{39,48}$ Simon et al ${ }^{47}$ first reported that 
pre-treatment with the competitive NMDA receptor antagonist 7-aminophosphonoheptanoic acid (APH) reduced acute ischemic hippocampal damage in vivo. Recent reports indicate that $\mathrm{MK}-801$, a noncompetitive NMDA antagonist acting at the phencyclidine site associated with the NMDA receptorchannel complex, is a potent neuroprotectant, reducing hypoxic-ischemic damage in vivo even when given after the initiation of the insult in both the immature ${ }^{31}$ and adult brain. ${ }^{17}$ Furthermore, MK-801 selectively attenuates neuronal damage in adult rats caused by intracerebral injection of NMDA but not kainic acid. ${ }^{14}$ This evidence suggests that neuronal damage in conditions related to glutamate toxicity is mediated, in part, by excessive NMDA receptor channel activation.

Several observations suggest that glutamate receptors and the severity of neurotoxicity mediated by glutamate analog undergo major changes during postnatal development. A dense pattern of glutamate receptors in the globus pallidus and basal forebrain of rodents develops soon after birth and is greatly diminished in adults. ${ }^{20}$ In contrast to the adult, the neonatal brain is relatively insensitive to kainic acid's neurotoxic effects. ${ }^{2}$ However, neonates are relatively more sensitive to the neurotoxic effects of quisqualic acid and NMDA.$^{33.46}$ In order to examine the neuroprotective effects of MK-801 during development, we tested the ability of MK-801 to antagonize NMDAor quisqualic acid-induced neurotoxicity in neonatal rats.

\section{EXPERIMENTAL PROCEDURES}

Seven-day-old male and female Sprague-Dawley albino rat pups (Charles River, MI), maintained on a $12 \mathrm{~h}: 12 \mathrm{~h}$ light:dark cycle, were used for these experiments and were housed with the dam at all times except for a 2-h experimental period. Intracerebral injections of excitotoxins were performed in seven-day-old pups briefly but deeply anesthetized with ether ${ }^{32}$ A midline cranial incision was made through the skin to expose the calvarium. Drugs were administered under stereotaxic guidance (Kopf small animal apparatus) using a Hamilton syringe with a 26-gauge needle. Pups were positioned in a plaster of Paris mold of the head and body. All intracerebral injections were directed into the posterior corpus striatum. Coordinates were AP $2.0 \mathrm{~mm}$, ML $2.5 \mathrm{~mm}$, at depth of $4.0 \mathrm{~mm}$ from the dura using bregma as a landmark. The needle was left in place for $2 \mathrm{~min}$ following injections to limit leakage.

Drugs were dissolved in $0.01 \mathrm{M}$ Tris, pH 7.4. Pups received either NMDA $(25 \mathrm{nmol} / 0.5 \mu 1)$, quisqualic acid $(100 \mathrm{nmol} / 1.0 \mu 1)$ or vehicle $(0.5 \mu 1)$ intrastriatally, MK-801 dissolved in phosphate-buffered saline (PBS, pH 7.4) was injected intraperitoneally (i.p.) in $0.05 \mathrm{ml}$. Control animals received equal volumes of PBS.

Two groups of MK-801 treatment protocols were used to assess neuroprotection using NMDA: (1) administration of a single dosage of MK-801 $(0.1,0.25,0.5,1.0 \mathrm{mg} / \mathrm{kg} ; n=9$. 7. 13,8 , respectively) $30 \mathrm{~min}$ prior to intrastriatal NMDA injection: (2) a single dose $(1 \mathrm{mg} / \mathrm{kg})$ at different time intervals in relation to NMDA injection $(-30,+30,40$. $120 \mathrm{~min} ; n=8,5,5,6$, respectively). A third protocol was used in which two doses of MK-801 were administered (each $1 \mathrm{mg} / \mathrm{kg}$ ), the first $30 \mathrm{~min}$ before and another immedi- ately following intrastriatal quisqualic acid administration $(n=6)$. Four additional groups served as controls: intrastriatal NMDA + i.p. PBS $(n=28)$, intrastriatal vehicle + i.p. PBS $(n=5)$, intrastriatal vehicle +i.p. MK-80l $(n=7)$ and intrastriatal quisqualic acid +i.p. PBS $(n-4)$. Appropriate littermate controls were included in each experiment on each day.

All pups were subsequently returned to the dam for five days and were decapitated on day 12. A five-day survival period allows sufficient time for brain edema to resolve (unpublished observations). Their brains were removed and placed sequentially into $10 \%$ phosphatebuffered formalin (PBF) followed by a $30 \%$ sucrose $/ \mathrm{PBF}$ solution. Fifty-micron frozen microtome coronal sections were stained for Nissl substance with Cresyl Violet. Tissue damage was assessed qualitatively by light microscopy and quantitated by measurement of cross-sectional areas of corpus striatum, dorsal hippocampus and cerebral hemisphere using a video-based computer-aided image analyser. For each animal, measurements were made bilaterally in four coronal sections through each individual structure corresponding to $0.7,1.0,1.3,1.6 \mathrm{~mm}$ (striatum, cerebral hemisphere) and 2.6.2.8,3.0,3.2 $\mathrm{mm}$ (hippocampus) caudal to bregma. The four measures for each structure were summed within animals by hemisphere and transformed by the formula $100 \times(C-I / C)$ into a term reflecting the degree of damage ( $\%$ damage) of the structure in the injected hemisphere relative to the contralateral structure. $C$ and $I$ refer to the cross-sectional areas of anatomical structures contralateral $(C)$ and ipsilateral $(I)$ to the lesioned hemisphere. The data were expressed as percentage protection (mean \pm S.E.M.) for each experimental group using the following formula:

$$
\%_{0} \text { protection }=100\left[1-\left(\frac{(C-I) / C}{\mathrm{MK}-80 I}\right)\right]
$$

Values for experimental groups that received MK-801 and an excitotoxin were compared with control groups that received an excitotoxin and saline.

Cortical electroencephalograms (EEGs) were recorded from seven-day-old rat pups at $1(n=12)$ and $4(n=8) \mathrm{h}$ after intracerebral injections of $25 \mathrm{nmol} / 0.5 \mu 1$ of NMDA. EEG activity was recorded independently from each cerebral hemisphere. To prepare pups for EEG recordings, they were briefly anesthetized with ether, the scalp was incised in the midline and five holes were made into the skull with a 26-gauge needle. Using bregma as a central landmark, electrodes were placed bilaterally at $\mathrm{AP}+3.75 \mathrm{~mm}$, ML $2.5 \mathrm{~mm}$ and $\mathrm{AP}-3.75 \mathrm{~mm}, \mathrm{ML} 2.5 \mathrm{~mm}$, and the ground was placed at a fifth site anteriorally and adjacent to the midline. Electrodes were secured at the epidural surface of the cortex with dental acrylic.

Electrodes were connected to a Grass P511J amplifier and EEG signals from each hemisphere were recorded simultaneously. Signals were amplified by a total gain of 20,000 . Active filters limited the signal to $1-40 \mathrm{~Hz}$. EEG signals were digitized and stored on magnetic tape. Representative 10 -min segments were printed. EEGs were recorded in four treatment groups: intrastriatal NMDA alone $(n=5)$, i.p. MK-801 (1 mg/kg) $30 \mathrm{~min}$ prior to intrastriatal NMDA $(n=5)$, i.p. MK-801 alone $(n=5)$, and untreated controls $(n=5)$. Recordings were made from pups at $1(n=3)$ and $4(n=2) \mathrm{h}$ after intrastriatal injection of NMDA.

Statistical comparisons consisted of two-tailed independent $t$-tests when two groups were compared and one-way ANOVA when multiple comparisons were made. Twoway ANOVAs were used when comparisons were made between groups with two variables (Systat, Fvanston, IL). The dependent variable in all tests was percentage damage $(C-I / C)$, except where noted otherwise. 


\section{Materials}

NMDA, quisqualic acid and other chemicals were obtained from Sigma (St Louis, MO). MK-801 was a gift from Dr P. Anderson (Merck, Sharp and Dohme, West Point, PA).

\section{RESULTS}

\section{Histological signs of N-methyl-D-aspartate neuro-} toxicity

Intracerebral NMDA injections into seven-day-old rats consistently produced extensive cellular necrosis, prominent gliosis, tissue loss and hemisphere deformity on the injected side when examined five days later (Fig. 1). Neuronal destruction was confluent in glutamate receptor-rich regions and within or directly adjacent to the injection site: corpus striatum, dorsal hippocampus and overlying neocortex. Tissue damage was always confined to the injected hemisphere and there appeared to be no microscopic signs of neuronal injury in the contralateral hemisphere. Other anatomical regions showing evidence of neuronal destruction included the lateral septal nuclei, septofimbrial nucleus, thalamic nuclei (ventral poste- rior medial, ventral posterior lateral, lateral dorsal ventrolateral, reticular), entopeduncular nucleus, and the subthalamic nucleus. More selective neuronal destruction was seen at the borders of the lesion and certain substructures were more vulnerable than others. For example, within the hippocampal subfields a hierarchical order of susceptibility to NMDA toxicity existed, $\mathrm{CA} 3>\mathrm{CA} 1>\mathrm{CA} 2$, and the dentate gyrus was relatively spared (especially the ventral blade). The cerebral cortical layers I-III were relatively resistant to NMDA toxicity. Selectivity in these cortical layers did not appear to reflect the distance from the injection site since direct intracortical injections of NMDA produced similar selective laminar necrosis (data not presented). The globus pallidus was partially resistant to intrastriatal NMDA injection with sparing of its intrinsic large multipolar neurons. This is consistent with the relative lack of NMDA receptors in this structure..$^{20}$ Other areas near the lesion which were unaffected included the nucleus accumbens, basolateral amygdala, cingulum and anterior commissure. Intrastriatal injection of vehicle did not produce any apparent signs of neuronal injury.
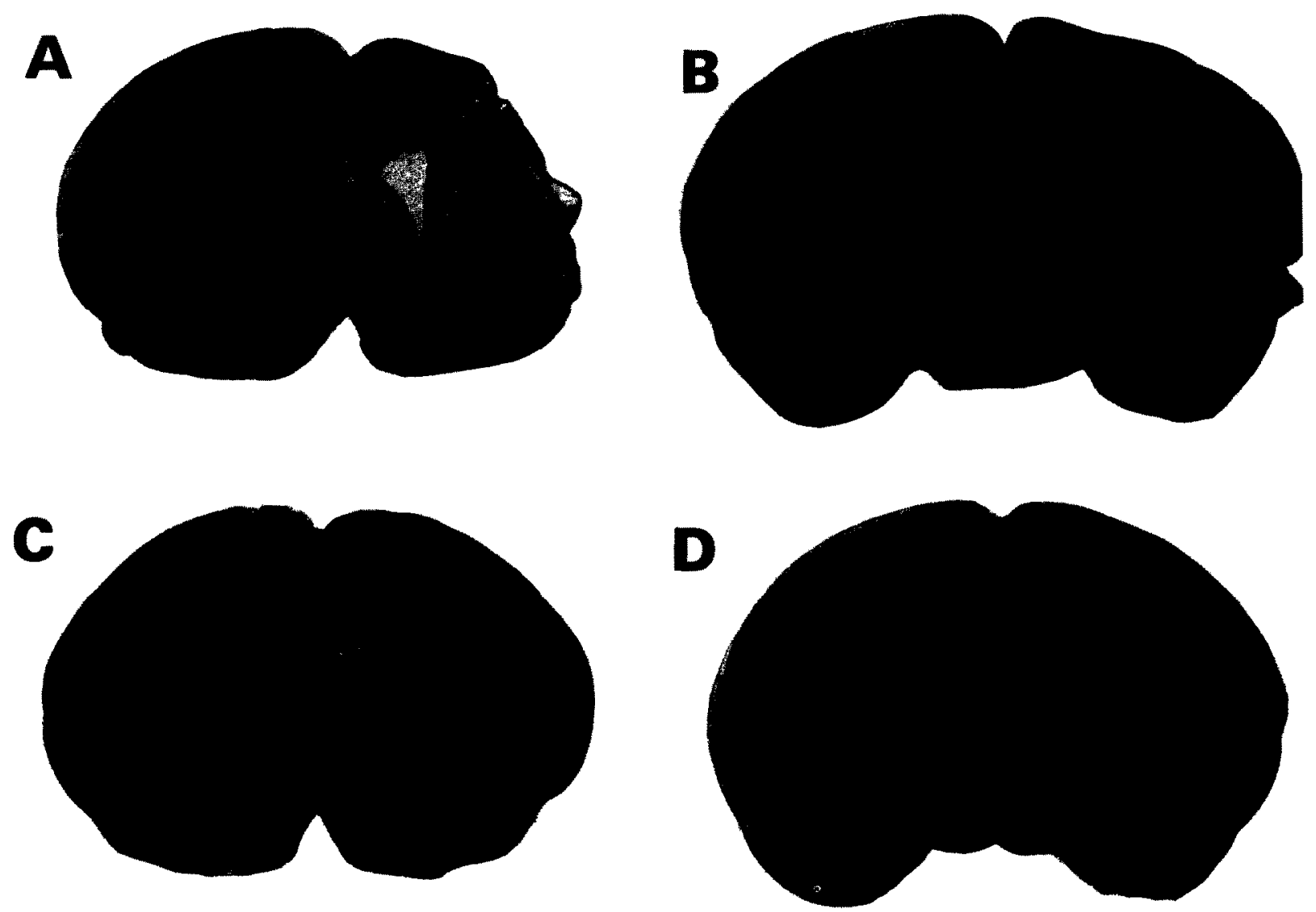

Fig. 1. Comparison of Nissl-stained coronal brain sections at the level of the striatum (A, C) and hippocampus $(B, D)$ from rat pups that received i.p. injections $(0.05 \mathrm{ml})$ of either $\mathrm{MK} \cdot 801(1.0 \mathrm{mg} / \mathrm{kg}$; C, D) or saline (A, B) 30 min prior to intrastriatal injection of NMDA $(25 \mathrm{nmol} / 0.5 \mu 1)$ on day 7 . Pups were killed five days later. Panels $A$ and B demonstrate the typical unilateral striatal and hippocampal neuropathologic lesion that results from intrastriatal injection of $25 \mathrm{nmol}$ NMDA. In contrast, there is little evidence of neuronal injury in animals pre-treated with MK-801 (panels C, D). Scale bar $=2 \mathrm{~mm}$. 
Neuroprotective effect of $M K-801$ on $\mathrm{N}$-methyl $-\mathrm{D}-$ aspartate histopathology

MK-801 (1 mg/kg) given $30 \mathrm{~min}$ prior to intra* striatal NMDA $(25 \mathrm{nmol} / 0.5 \mu \mathrm{l})$ protected completely against both the gross and microscopic features of its neurotoxicity (Fig. 1). Neuroprotective effects of varying doses of $\mathrm{MK}-801$ on neurotoxicity of a fixed dose of NMDA are illustrated in coronal sections through the striatum (Fig. 2) and hippocampus (Fig. 3). Confluent necrosis, neuronal destruction, gross tissue deformation and widening of the ipsilateral ventricle were evident in animals pre-treated with $0.1 \mathrm{mg} / \mathrm{kg}$ of $\mathrm{MK}-801$. A dose of $0.25 \mathrm{mg} / \mathrm{kg}$ substantially reduced confluent neuronal necrosis and the striatum and hippocampus were structurally preserved although reduced in size. It is noteworthy that this dose protected the cortex nearly completely and when damage was present it was usually confined to layer VI. Pre-treatment with $0.5 \mathrm{mg} / \mathrm{kg}$ MK-801 eliminated the gross signs of NMDA neurotoxicity and reduced the glial response. Striatal size was reduced on the injected side with little change in hippocampal and cerebral hemisphere size. Myelinat- ing fasicles within the striatum appeared to be relatively preserved.

MK-801 (1 mg/kg) also effectively antagonized NMDA toxicity when given 30,40 or 120 min after intrastriatal NMDA injections. MK-801 given after 30 or 40 min totally prevented gross NMDA toxicity and when treatment was delayed for $2 \mathrm{~h}$, the only histopathologic changes were gliosis adjacent to the injection site and a slightly enlarged lateral ventricle corresponding with a reduction in the size of the striatum on that side. Thus, the striatum, which receives the maximal dose of NMDA, was the only structure substantially damaged by NMDA in animals post-treated with MK-801 at $2 \mathrm{~h}$. This pattern was similar to the distribution of injury in animals pre-treated with intermediate $(0.25$ or $0.5 \mathrm{mg} / \mathrm{kg}$ ) doses of MK-801. MK-801 did not appear to have obvious adverse neuropathological effects in control pups.

Quantitative evaluation of effects of $M K-801$ on $\mathrm{N}$ methy-D-aspartate toxicity

The neuroprotective effects of MK-801 on NMDA neurotoxicity were quantified using a video-based
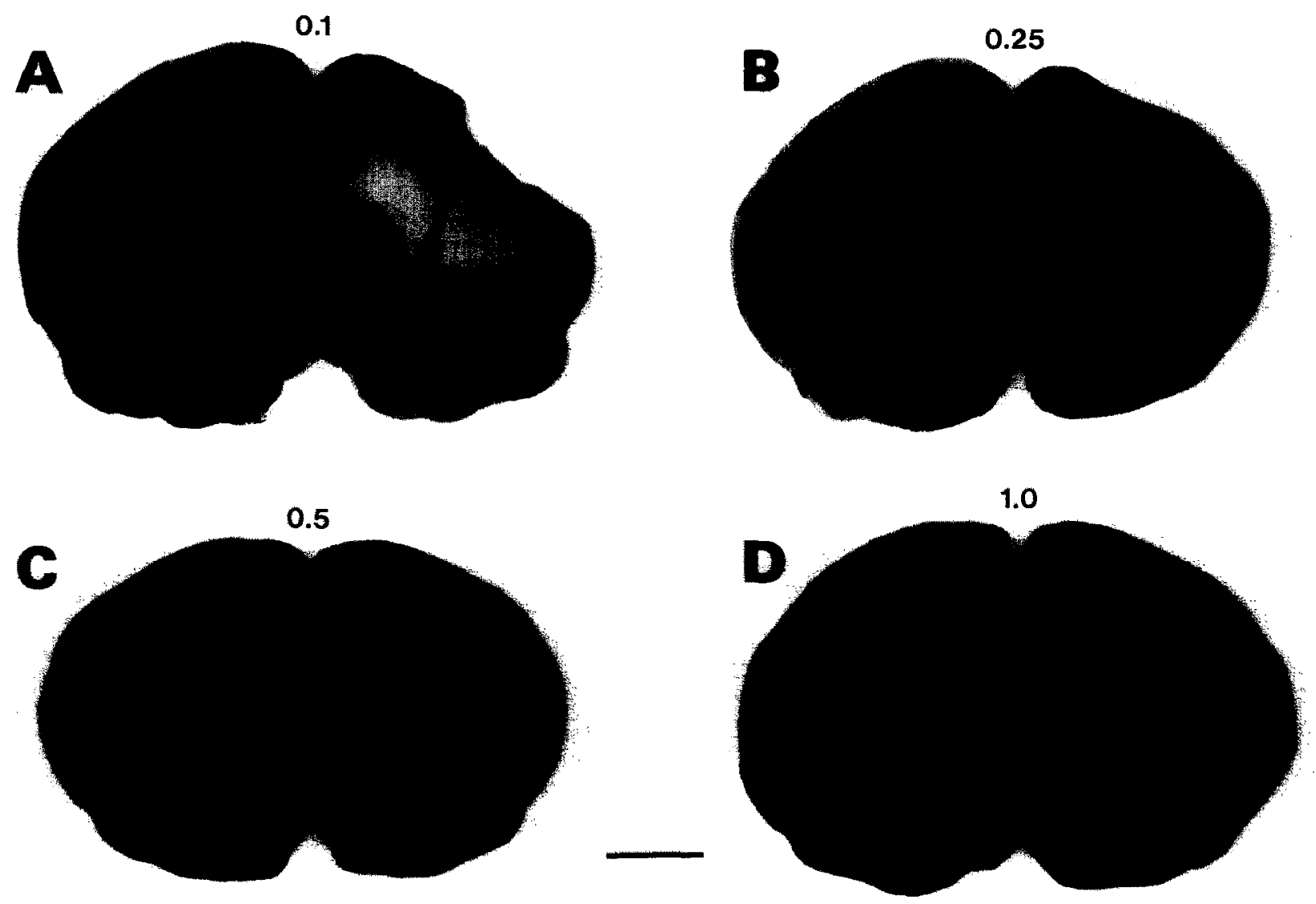

Fig. 2. Comparison of neuroprotective effect of increasing dosages of MK-80l against NMDA-induced neuronal damage assessed in Nissl-stained coronal brain sections of 12-day-old rat pups. MK-801 was administered (i.p. injection, $0.05 \mathrm{ml}$ ) $30 \mathrm{~min}$ prior to intrastriatal injection of NMDA $(25 \mathrm{nmol} / 0.5 \mu$ ) in seven-day-old pups. Pups were killed five days later. Panel A, 0.1; B, 0.25, C, 0.5;D, $1.0 \mathrm{mg} / \mathrm{kg} \mathrm{MK-801}$. Panel A shows a similar extent of injury as is present in pups pre-ireated with saline. With higher doses of MK-80l there is a progressive reduction in the extent of tissue injury. Scale bar $=2 \mathrm{~mm}$. 
0.1

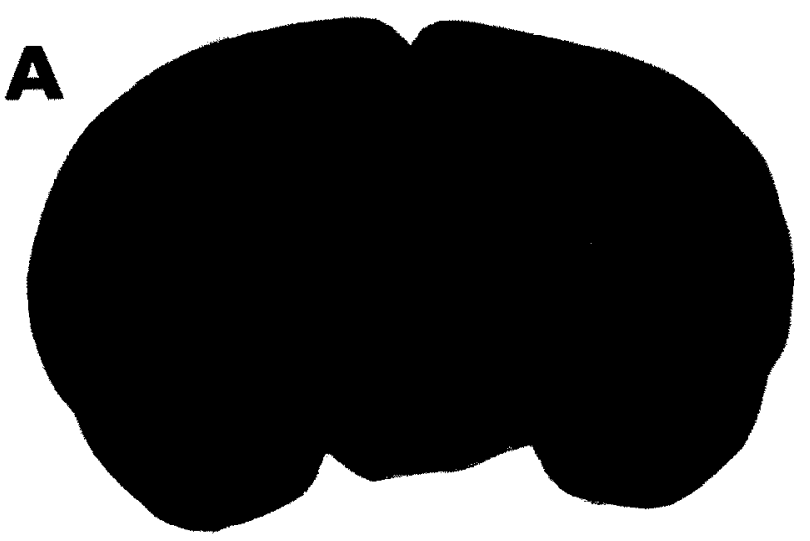

0.5

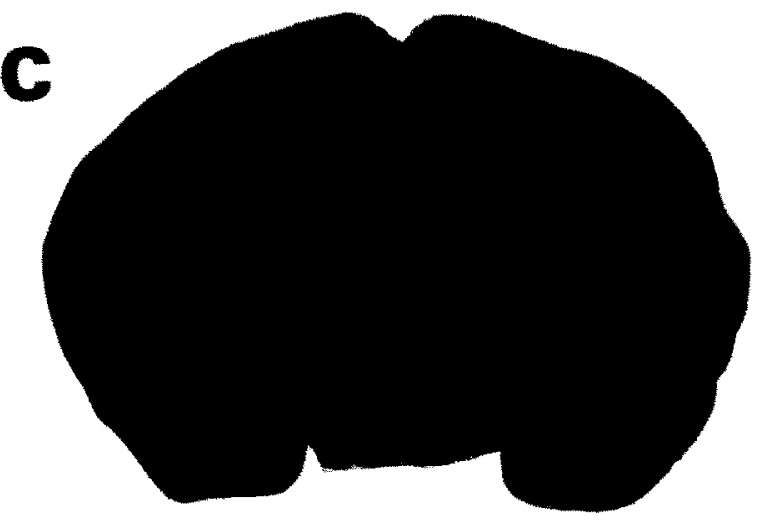

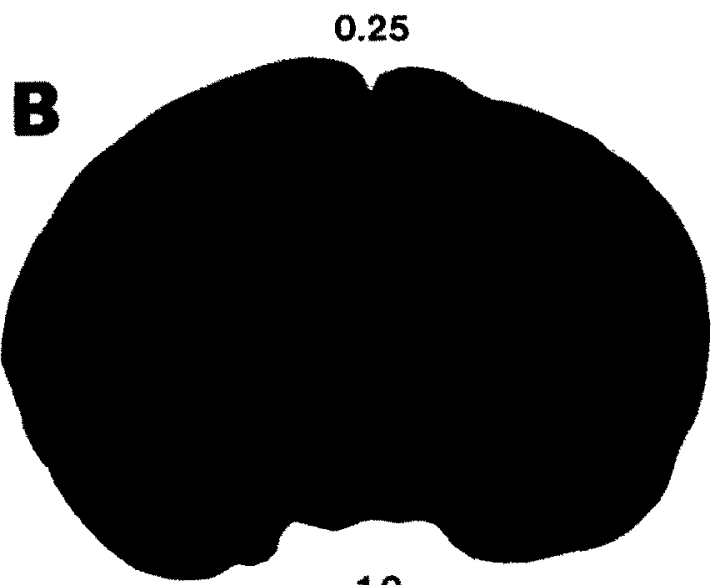

1.0

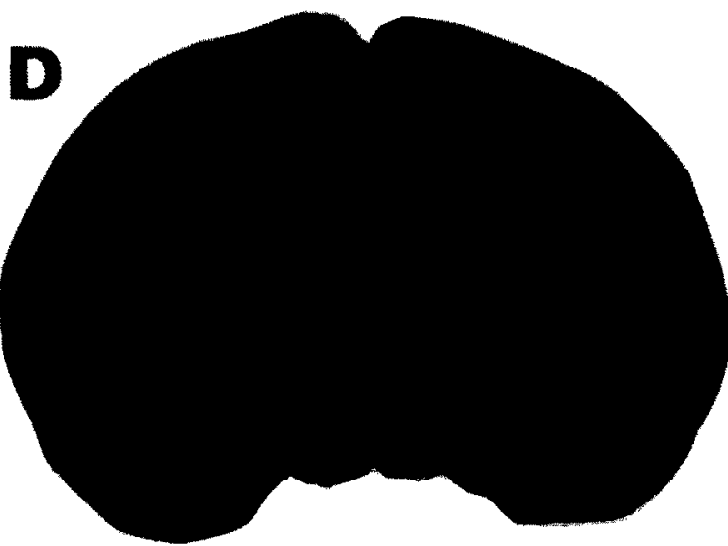

Fig. 3. Comparison of Nissl-stained coronal brain sections through the hippocampus of 12-day-old rat pups that were pre-treated with increasing dosages of MK-801 (i.p. injection, $0.05 \mathrm{ml}) 30 \mathrm{~min}$ prior to intrastriatal injection of NMDA $(25 \mathrm{mmol} / 0.5 \mu \mathrm{l})$ on day 7 . Panel $\mathrm{A}, 0.1 ; \mathrm{B}, 0.25 ; \mathrm{C}, 0.5 ; \mathrm{D}, 1.0 \mathrm{mg} / \mathrm{kg}$ MK-801. MK-801 at a $0.1 \mathrm{mg} / \mathrm{kg}$ dose (panel A) was not neuroprotective, while a $1.0 \mathrm{mg} / \mathrm{kg}$ dose was completely protective. Scale bar $=2 \mathrm{~mm}$.

computerized image analyser to measure the crosssectional areas of the corpus striatum, dorsal hippocampus and cerebral hemisphere bilaterally in coronal brain sections of animals pre-treated with increasing doses $(0.1,0.25,0.5,1.0 \mathrm{mg} / \mathrm{kg})$ of MK-801 or post-treated at varying latencies $(30,40,120 \mathrm{~min})$ with $\mathrm{MK}-801$ (1 mg/kg) following intrastriatal NMDA injections $(25 \mathrm{nmol} / 0.5 \mu \mathrm{l})$. The shrinkage in cross-sectional areas corresponded to the severity of the microscopic changes observed. NMDA caused a consistent loss of tissue cross-sectional area in the striatum $(-59.6 \pm 3.1 \%$ decrease in the area of the injected hemisphere relative to the opposite side), hippocampus $(-50.3 \pm 3.1 \%)$ and cerebral hemisphere $(-36.9 \pm 3.2 \%)$ on the lesioned side compared to the opposite side $(P<0.001$, paired $t$-test, $n=28$ ). The size of the contralateral hemisphere of animals injected with NMDA was significantly reduced in comparison with that of saline-injected controls; cross-sectional areas (mean \pm S.E.M.) of striatum were $6.50 \pm 0.11 \mathrm{~mm}^{2}$ saline-injected, $n=5$, vs $\quad 5.76 \pm 0.11 \mathrm{~mm}^{2} \quad$ NMDA-injected, $n=26$, $P<0.005$, one-way ANOVA. MK-801 treatment produced significant dose-dependent neuroprotection $(P<0.001$, two-way ANOVA, MK-801-treated vs NMDA controls; $n=37,28$, respectively) with virtually $100 \%$ protection achieved in pups pre-treated with a $1 \mathrm{mg} / \mathrm{kg} \mathrm{MK-801} \mathrm{dose} \mathrm{(Fig.} \mathrm{4).} \mathrm{Tissue} \mathrm{damage}$ was also evident in pups pre-treated with lower doses of $\mathrm{MK}-801 ; 0.5 \mathrm{mg} / \mathrm{kg}$ or $0.25 \mathrm{mg} / \mathrm{kg}$ of $\mathrm{MK}-801$ protected against 75 or $50 \%$ of tissue loss respectively in all three regions studied $(P<0.001$, one-way ANOVA, MK-801-treated vs NMDA controls). At the lowest dose $(0.1 \mathrm{mg} / \mathrm{kg})$ the extent of damage in the striatum was nearly identical to that of controls, but there was significant neuroprotection in the hippocampus and a similar trend in the cerebral hemisphere $(48 \pm 11 \%, P<0.001$ and $25 \pm 5 \%$ protection, respectively).

In animals treated with $\mathrm{MK}-801$ at 30 or $40 \mathrm{~min}$ after NMDA injection, comparison of bilateral crosssectional areas demonstrated statistically significant neuronal protection in the hippocampus and cerebral hemisphere (Fig. $5 ;>90 \%$ protection, $P<0.001$ one-way ANOVA, MK-801-treated, $n=10$, vs NMDA controls, $n=28$ ). MK-801 at these times was 
DOSE EFFECT OF MK-801 TREATMENT ON NMDA NEUROTOXICITY
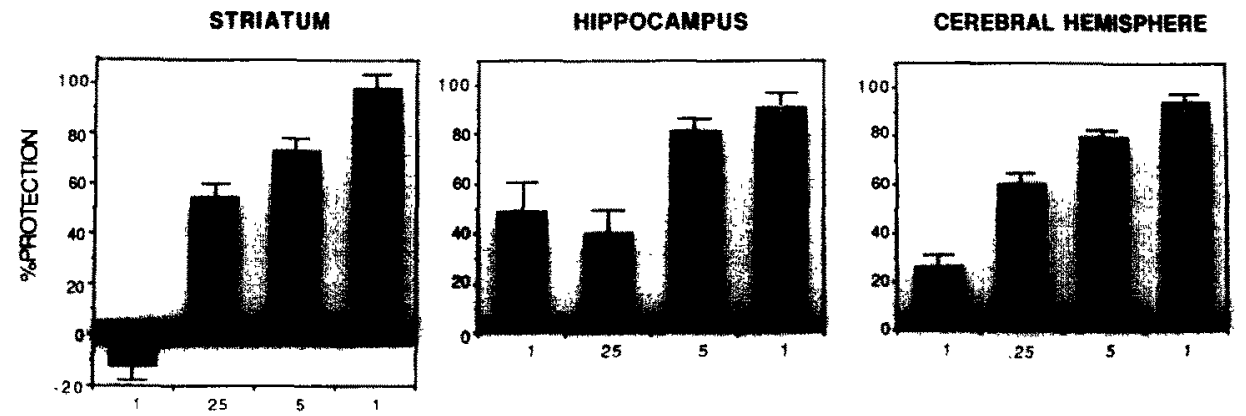

DOSE OF MK-801 (mg/kg)

Fig. 4. Neuroprotective potency of increasing dosages of MK-801 in pups pre-treated with MK-801 $(0.1$, $0.25,0.5,1.0 \mathrm{mg} / \mathrm{kg} ; n=9,7,13,8) 30 \mathrm{~min}$ prior to intrastriatal injection of NMDA $(25 \mathrm{nmol})$. Tissue damage was assessed by measurement of regional cross-sectional areas (see Experimental Procedures). Cross-sectional areas of the striatum, hippocampus and cerebral hemisphere were measured bilaterally in four sections through each structure. In individual animals, values for each structure were summed by hemisphere and transformed by the formula $(C-I) / C$ into a term reflecting the degree of damage of the injected hemisphere. $C$ and $I$ refer to the cross-sectional areas of structures contralateral and ipsilateral to the lesioned hemisphere. The data were expressed as percentage protection (mean \pm S.E.M.) for each experimental group using the formula given in Experimental Procedures. "MK-801" groups received MK-801 prior to intrastriatal NMDA whereas "control" pups were administered saline. The shaded region represents the S.E.M. for the saline-treated NMDA-injected controls. All but the lowest dose of MK-801 produced significant neuroprotection in the striatum, the site of NMDA injection. Significant protection from NMDA-induced damage was also achieved by all doses of $\mathrm{MK}-801$ in the hippocampus and cerebral hemisphere $(P<0.001$, one-way ANOVA, MK-801 group vs saline-treated NMDA-injected controls).

TIME EFFECT OF MK-801 TREATMENT ON NMDA NEUROTOXICITY

STRIATUM

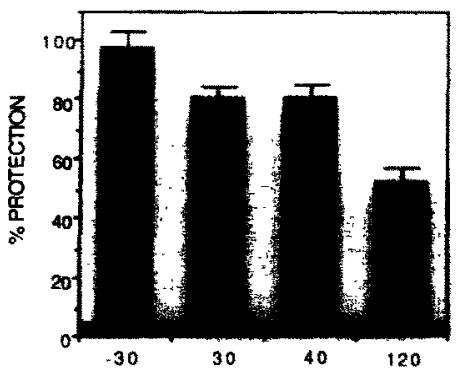

HIPPOCAMPUS

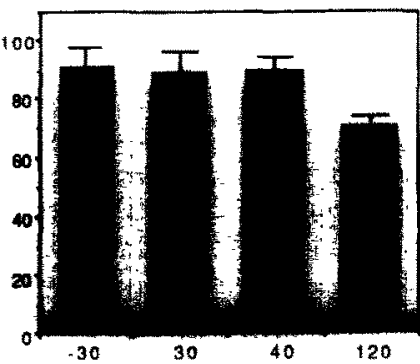

CEREBRAL HEMISPMERE

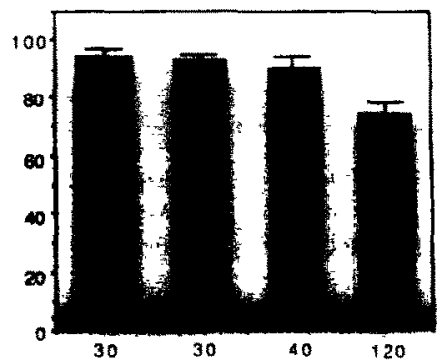

TIME OF MK-801 TREATMENT RELATIVE TO NMOA INJECTION (MIN)

Fig. 5. Effect of timing of MK-801 treatment on the extent of NMDA-induced tissue injury in seven-day-old rats that received an intrastriatal injection of NMDA $(25 \mathrm{nmol})$. MK-801 (1 mg/kg i.p.) was administered $30 \mathrm{~min}(n=8)$ prior to and $30(n=5), 40(n=5)$, or $120(n=6)$ min after the injection of NMDA. Cross-sectional areas of the striatum, hippocampus, and cerebral hemisphere were measured and expressed as percentage protection (see Fig. 4). Data are expressed as the mean \pm S.E.M. and the shaded region represents the S.E.M. for the control group that received NMDA intrastriatally $(n=28)$. Treatment with MK-801 resulted in significant neuroprotection at all time points $(P<0.001$, one-way ANOVA.

$$
\text { MK-801-treated vs saline-treated NMDA-injected controls). }
$$


slightly less effective in the striatum, achieving $80 \pm 5 \%$ protection $(P<0.001)$. Even $2 \mathrm{~h}$ after the insult, the neuroprotective effects of $\mathrm{MK}-801$ were substantial: $70 \pm 4 \%$ protection in the hippocampus and cerebral hemisphere, and $50 \pm 5 \%$ in the striatum $(P<0.001, n=6)$.

\section{Quantitation of effect of $M K-801$ on quisqualate toxicity}

MK-801 also provided some protection against quisqualic acid-induced neuronal injury (Fig. 6). The cross-sectional areas on the lesioned side of quisqualic acid-treated pups were consistently reduced compared to the opposite side (striatum, $-37.5 \pm$ $5.1 \%$; hippocampus, $-56.5 \pm 3.5$; cerebral hemisphere, $-11.5 \pm 3.7 \% \quad P<0.001$, paired $t$-test, $n=4$ ). It is noteworthy that the hippocampus was more susceptible to quisqualic acid-induced toxicity than was the striatum, whereas both are equally effected by NMDA. A $1 \mathrm{mg} / \mathrm{kg}$ dose of MK-801 administered i.p. twice, 30 min prior to and immediately after intrastriatal quisqualic acid injection $(100 \mathrm{nmol} / 1.0 \mu \mathrm{l})$, was significantly protective in the striatum $(40 \pm 7 \%$, protection, $P<0.02$, independent $t$-test, MK-801-treated vs QA-injected controls) with a similar though not statistically significant trend observed in the cerebral hemisphere $(56 \pm 19 \%$ protection). This dose was, however, less effective in the hippocampus $(20 \pm 8 \%$ protection). A single dose of MK-801 has not been examined.

Effects of $M K-801$ and $\mathrm{N}-$ methyl-D-aspartate on behavioral and electroencephalogram activity

In saline-treated pups, intrastriatal NMDA injection caused turning behavior to the side of injection and increased locomotion within $20 \mathrm{~min}$ of initial recovery from ether anesthesia. Severe generalized, tonic and tonic-clonic seizures were evident $45 \mathrm{~min}$ after NMDA administration, an effect which typically endured for several hours. The seizures generally prevented an upright posture. MK-801 $(1 \mathrm{mg} / \mathrm{kg})$ blocked the behavioral signs of NMDAinduced seizures within 2-5 min of i.p. administration. MK-801 pre-treatment facilitated induction and deepened the level of anesthesia produced by ether. Animals injected with MK-801 displayed a progressive set of behaviors. Initially, pups exhibited intermittent unidirectional turning and a general increase in locomotion. This behavior was still present $12 \mathrm{~h}$ after administration of MK-801 although it was less frequent. Following the initial period of behavioral excitation pups exhibited decreased muscle tone and a behavioral state of mild sedation. These effects were still present $24 \mathrm{~h}$ post-treatment.

EEG recordings from saline-treated pups that received NMDA showed intermittent bihemispheric synchronous high-yoltage, high-frequency epileptiform discharges. High-voltage and high-frequency discharges were present in the injected hemisphere at both $1(n=3)$ and $4(n=2)$ h post-NMDA

\section{EFFECT OF MK-801 TREATMENT ON QUISQUALIC ACID NEUROTOXICITY}

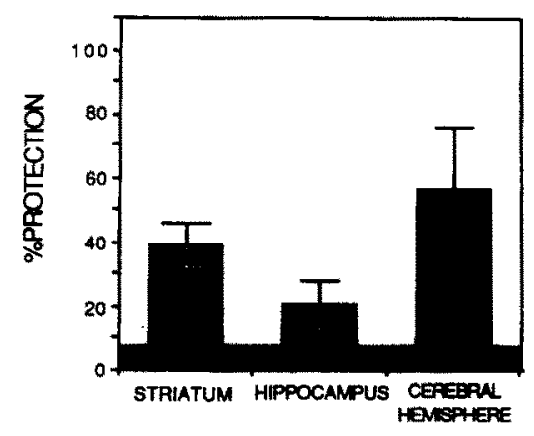

Fig. 6. Effect of MK-801, a non-competitive NMDA antagonist, on the neurotoxicity produced by intrastriatal injection of the glutamate receptor agonist quisqualic acid in seven-day-old rat pups $(n=6)$. MK-801 $(1 \mathrm{mg} / \mathrm{kg}$ per dose) was administered i.p. $30 \mathrm{~min}$ before and immediately after injection of quisqualic acid $(100 \mathrm{nmol} / 1.0 \mu \mathrm{l})$. Data (mean \pm S.E.M.) were expressed as percentage protection (see Fig. 4 legend) and compared to saline-treated quisqualic acid-injected controls. The shaded bar is the S.E.M. for the quisqualic acid-injected control group $(n=4)$. MK-80I treatment produced significant protection against quisqualic acid-induced damage in the striatum $(P<0.02$, independent $t$-test, MK-801-treated $n=6$ vs saline-treated controls $n=4$ ) with a similar trend in the cerebral hemisphere. In contrast, less protection was achieved in the hippocampus.

(Fig. 7). EEGs from animals given either MK-801 alone $(n=5)$ or MK-801 plus NMDA $(n=5)$ showed marked voltage and frequency suppression (Fig. 7). Few paroxysmal discharges were recorded in NMDA-treated pups that received MK-801.

\section{DISCUSSION}

The NMDA receptor is coupled to a cationic membrane channel at which activity is regulated by glycine, $\mathrm{Mg}^{2+}, \mathrm{Zn}^{2+}$ and phencyclidine receptor ligands. $22.29,30,40,43$ NMDA receptor activation results in $\mathrm{Ca}^{2+}$, and $\mathrm{Na}^{2+}$ influx into the cell followed by passive $\mathrm{Cl}^{-}$influx. Excessive receptor activation results in intracellular $\mathrm{Ca}^{2+}$ accumulation, neuronal injury and death. ${ }^{4,5.16 .38,41}$ Unilateral injections of NMDA $(25 \mathrm{nmol} / 0.5 \mu 1)$ into the posterior striatum of seven-day-old rats produced a consistent and reproducible lesion characterized by confluent necrosis, gross tissue deformation, and reactive gliosis predominantly affecting the corpus striatum, dorsal hippocampus and overlying neocortex in the lesioned hemisphere. This pattern of damage corresponds with NMDA receptor distributions within the immature brain (unpublished observations). Selectively vulnerable nuclei at the periphery of the lesion included the lateral septal, septofimbrial, thalamic and entopedunclular nuclei, areas which correspond to putative glutamatergic pathways and their terminal receptive fields. ${ }^{8.12 .44}$ 


\section{A. CONTROL}

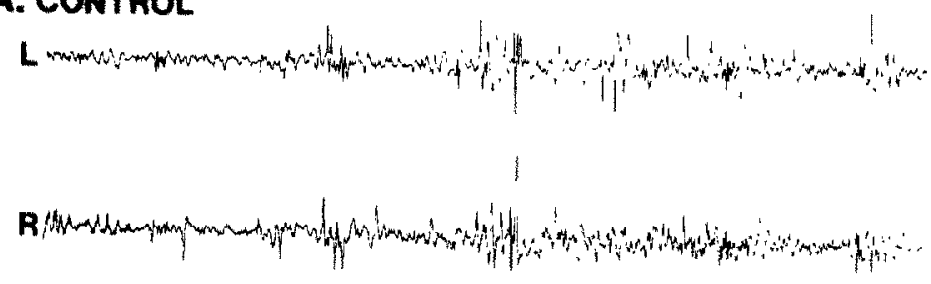

\section{B. MK-801}

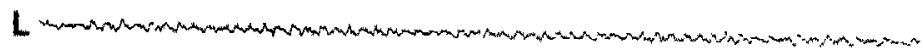

$\mathbf{R}$

C. NMDA

L Hothow

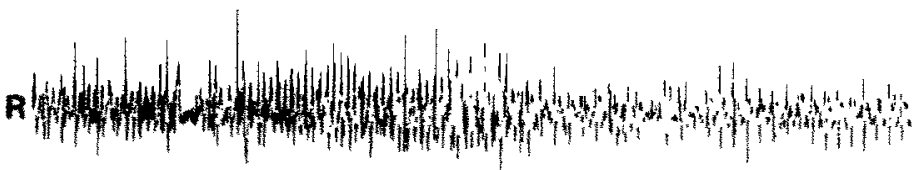

\section{NMDA + MK-801}

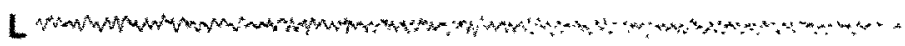

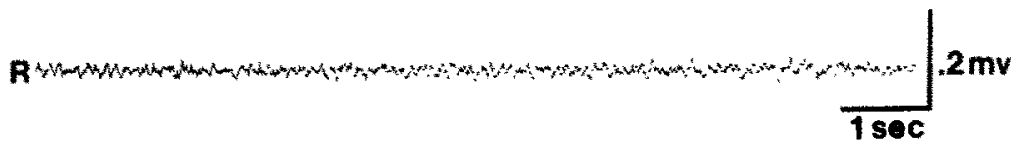

Fig. 7. Cortical EEGs from left and right hemispheres of seven-day-old rat pups illustrating the typical EEG tracings from untreated pups (A) and from animals that received MK-801 (B), NMDA (C), or both NMDA and MK-801 (D). See Experimental Procedures for details of EEG recording procedure. NMDA $(25 \mathrm{nmol} / 0.5 \mu 1)$ was injected intrastriatally. MK-801 $(1 \mathrm{mg} / \mathrm{kg})$ or PBS was administered (i.p. in $0.05 \mathrm{ml})$ 30 min prior to the intrastriatal injection of NMDA or saline. Tracings were recorded from the cerebral hemisphere epidural surface bilaterally for $10 \mathrm{~min}, 1 \mathrm{~h}$ after the injection of NMDA. Injection of NMDA results in marked epileptiform activity in both cerebral hemispheres. MK-801 produced matkedly reduced EEG activity in normal animals as well as pups that received NMDA. The upper trace for each group is the recording from the left hemisphere. Each trace represents $10 \mathrm{~s}$ and the vertical scale bar is equivalent to $0.2 \mathrm{mV}$.

Possible site of action of $M K-801$ in developing brain

The data demonstrate that systemically administered MK-801 prevents NMDA-induced neuronal necrosis in the immature rat brain in a dose-dependent fashion $(0.1 \mathrm{~m} 1 \mathrm{mg} / \mathrm{kg})$. Complete neuroprotection was achieved with a $1 \mathrm{mg} / \mathrm{kg} \mathrm{MK-801} \mathrm{dose} \mathrm{given}$ i.p. $30 \mathrm{~min}$ prior to intrastriatal injection of $25 \mathrm{mmol}$ NMDA. Near-complete protection was also achieved in animals post-treated with $\mathrm{MK}-801(1 \mathrm{mg} / \mathrm{kg}$, i.p.) 30 or 40 min after intrastriatal NMDA injections. However, if the NMDA-induced events are allowed to proceed for $2 \mathrm{~h}$ prior to $\mathrm{MK}-801$ treatment, sub- stantial neuronal damage results. A $30 \%$ reduction is found in the cross-sectional area of the hippocampus and cerebral hemisphere of the injected hemisphere, and a $50 \%$ decrease is found in the striatum, the site of NMDA injection. This suggests that a critical time window exists in the evolution of NMDA-mediated injury within which treatment with MK-801 provides protection.

The dose of MK-801 required to achieve complete protection in the immature rat is considerably lower than the dose required to achieve complete protection in the adult rat brain as reported by Foster $e t a l^{14}$ (1 vs $10 \mathrm{mg} / \mathrm{kg}$ ). These findings, in addition to other reports, may indicate that non-competitive NMDA 
antagonists are more effective in the developing brain."

It is noteworthy that MK-801 also partially protected against quisqualic acid neurotoxicity. These findings were unexpected since MK-801 has been considered a selective NMDA antagonist, based on its failure to antagonize kainic acid-induced neuronal injury and kainic acid- and quisqualic acid-mediated electrophysiological responses in adult rat preparations. ${ }^{2,54}$ MK-801 may attenuate quisqualic acidinduced brain damage by limiting secondary glutamate release and subsequent activity of NMDA receptors. Although commercially available quisqualic acid may be contaminated with glutamate, intracerebral administration of glutamate $(1 \mu \mathrm{mol})$ does not produce brain injury (unpublished observation). Thus, it is unlikely that exogenous glutamate contributes to quisqualic acid neurotoxicity in this model.

Interestingly, cortical layers IV and VI were destroyed with selective preservation of cortical layer $V$ neurons in quisqualic acid-injected animals treated with MK-801. Similar results were occasionally found in pups that received only quisqualic acid, although less frequently. This observation may suggest that cells of cortical layers IV and VI have higher concentrations of quisqualic acid receptors.

Quisqualic acid- and NMDA-type EAA receptors may be involved in hypoxic-ischemic brain injury in immature rats, and the present data suggest that MK-801 may protect against both types of damage. At this age, kainate receptor-mediated damage probably contributes little damage directly in hypoxia-ischemia since kainic acid is not very neurotoxic at such an age. ${ }^{2}$ High densities of quisqualic acid receptors are expressed transiently in vulnerable regions of immature mammalian brain and direct injection of quisqualic acid into the seven-day-old rat brain causes neuronal damage and seizures. ${ }^{3,20,46}$ The widespread neuroprotective effect of MK-801 in experimental hypoxia-ischemia includes sites rich in quisqualic acid-preferring sites as well as those with a higher density of NMDA sites.

Neurotoxic effects of $\mathrm{N}-$ methyl-D-aspartate in developing versus adult brain

In comparison to reports describing NMDA neurotoxicity in adult rats, the developing CNS seems considerably more sensitive to NMDA toxicity. $14,33,50$ Administration of $25 \mathrm{nmol}$ of NMDA intrastriatally in the seven-day-old rat produces confluent necrosis involving the entire cerebral hemisphere, resulting in a $37 \%$ decrease in the cross-sectional area five days later. In additional studies, a similar injection produced a $28 \%$ decrease in the weight of the injected hemisphere after similar delay. ${ }^{34}$ In contrast, we found that injections of $75 \mathrm{nmol} / 1.5 \mu 1$ NMDA in adult rat striatum produced minimal neuronal damage without gross tissue deformation and destruction. $^{33}$

The apparent developmental change in NMDA toxicity may reflect alterations in receptor numbers, receptor-ligand interaction, receptor-channel coupling, modulation of channel activation (e.g. by glycine, $\mathrm{Zn}^{2+}, \mathrm{Mg}^{2+}$ ) or in the events leading to neuronal injury that may follow excessive NMDA receptor activation. In vitro autoradiographic studies indicate that NMDA and phencyclidine receptor binding is six- to eight-fold lower in seven-day-old rats in comparison to adults (unpublished observation). There have been no reports indicating developmental changes in the coupling of the NMDA receptors to the channel, or in the mechanisms of channel regulation. Differences in the distribution, uptake, metabolism, and/or elimination of NMDA between immature and adult rats could account for part of the observed age-related effect. For example, the more heavily myelinated adult brain may limit diffusion. Furthermore, during the experimental period (7-12 days postnatal) the rat pups are undergoing rapid brain growth and this may alter the evolution of the lesion.

The relative ability of EAA agonists to produce neurotoxicity is also altered during development: the rank order of potency in adult rat brain is kainic acid $\gg N M D A \geqslant$ quisqualic acid, in contrast to NMDA $\gg$ quisqualic acid $\gg$ kainic acid in sevenday-old rat brain. ${ }^{2,9,21,46,55}$ Additionally, quinolinic acid, an NMDA receptor agonist, is a potent toxin in adult rats; however, it lacks neuronal toxicity in seven-day-old rats. ${ }^{13}$ These age-related neurotoxic effects do not reflect simple alterations in ligand receptor numbers. For instance, NMDA receptor binding is reduced in vulnerable regions of the brain in seven-day-old rats compared to adults while quisqualic acid binding is about equivalent to that of adults.

Direct injection of NMDA into the seven-day-old rat brain provides a highly reproducible, convenient, quantiative system for evaluating potential neuroprotective drugs. Parallels of the model with experimental hypoxic-ischemic brain injury suggest that compounds with neuroprotective activity in this preparation may also be active against ischemic neuronal necrosis. This model should also allow secondary metabolic effects of EAA neurotoxicity in the intact brain to be studied in isolation from pathogenetic models of hypoxia-ischemia-mediated neuronal injury.

Acknowledgements-This work was supported by USPHS grants IP0INS19613 (M.V.J.), MSTP grant 5 T32 6M07863-07 (J.W.M.), IK08NS01171 (F.S.S.), grant R-326 from the United Cerebral Palsy Research and Education Foundation (M.V.J) and a grant from the Epilepsy Foundation on America (F.S.S.). MK-801 was a gift of Dr P. Anderson Merck, Sharp and Dohme, West point, PA. We thank K. Gordon, C. Chen and D. Statman for assistance and Holly Arft for expert preparation of the manuscript. 


\section{REFERENCES}

1. Anis N. A., Berry S. C., Burton N. R. and Lodge D. (1983) The dissociative anesthetics, ketamine and phencyclidine, selectively reduce excitation of central mammalian neurons by $N$-methyl-D-aspartate. $B r, J$. Pharmac. 79 , $565-575$.

2. Campochiaro $P$. and Coyle $J$. T. (1978) Ontogenetic development of kainate neurotoxicity: correlates with glutamatergic innervation. Proc. natn. Acad. Sci. U.S.A. 75, $2025-2029$.

3. Chen R., Silverstein F. S., Aldridge W. and Johnston M. V. (1986) Evolution of acute cortical EEG changes in experimental perinatal hypoxic-ischemic encephalopathy. Neurology 36 (Suppl. 1), 86.

4. Choi D. W., Maulucci-Gedde M. and Kriegstein A. R. (1987) Glutamate neurotoxicity in cortical cell culture. $J$. Neurosci. $7,357-368$.

5. Choi D. W. (1987) Ionic dependence of glutamate neurotoxicity. $J$. Neurosei. 7, 369-379.

6. Clineschmidt B. V., Martin G. E. and Bunting P. R. (1982) Anticonvulsant activity of (+)-5-methyl-10, 11-dihydro-5Hdibenzo[ $a, d]$ cyclohepten-5, 10-imine (MK-801) a substance with potent anticonvulsant, central sympathomimetic, and apparent anxiolytic properties. Drug Devl. Res. 2, 123-124.

7. Cook T. M. and Crutcher K. A. (1986) Intrahippocampal injection of kainic acid produces significant pyramidal cell loss in neonatal rats. Neuroscience 18, 79-92.

8. Cotman C. W., Monaghan D. T., Ottersen O. P. and Storm-Mathisen J. (1987) Anatomical organization of excitatory amino acid receptors and their pathways. Trends Neurosci. 10, 273-280.

9. Coyle J. T. (1982) Excitatory amino acid neurotoxins. In Handbook of Psychopharmacology (eds Iversen L. L., Iversen S. D. and Snyder S. H.), Vol. 15, pp. 237-269. Plenum Press, New York.

10. Davies J., Evans R. H., Jones A. W., Mewett K. N., Smith D. A. A. and Watkins J. C. (1983) Recent advances in the pharmacology of excitatory amino acids in the mammalian central nervous system. In Excitotoxins (eds Fux K., Roberts P. J. and Schwarcz R.). pp. 43-54. Plenum Press. New York.

11. Flatman J. A., Schwindt P. C.. Crill W. E. and Afstrom S. T. (1983) Multiple actions of $N$-methyl-D-aspartate on cat neocortical neurons in vitro. Brain Res. 226, 169-173.

12. Fonnum F. (1984) Glutamate: a neurotransmitter in mammalian brain. J. Neurochem. 42, 1-11.

13. Foster A. C., Collins J. F. and Schwarcz R. (1983) On the excitotoxic properties of quinolinic acid, 2-3-piperidine dicarboxylic acids and structurally related compounds. Neuropharmacology 22, 13311342.

14. Foster A. C., Gill R., Kemp J. A. and Woodruff G. N. (1987) Systemic administration of MK-801 prevents $N$-methyl-D-aspartate induced neuronal degeneration in rat brain. Neurosci. Lett. 76, 307-311.

15. Foster G. A. and Roberts P. J. (1980) Pharmacology of excitatory amino acid receptors mediating the stimulation of rat cerebellar cyclic GMP levels in vitro. Life Sci. 27, 215-221.

16. Fuxe K., Roberts P. and Schwarcz R. (eds) (1983) Excitotoxins. Plenum Press, New York.

17. Gill R., Foster A. C. and Woodruff G. N. (1987) Systemic administration of MK-801 protects against ischemia-induced hippocampal neurodegeneration in the gerbil. $J$. Neurosci. $7,3343-3349$.

18. Greenamyre J. T. Young A. B. and Penney J. B. (1984) Quantitative autoradiographic distribution of L- ${ }^{3} \mathrm{H}$-glutamate binding sites in rat central nervous system. $J$. Neurosci. 4, 2133-2144.

19. Greenamyre J. T., Olson J. M. M., Perney J. B. and Young A. B. (1985) Autoradiographic characterization of $N$-methyl-D-aspartate, quisqualate- and kainate-sensitive glutamate binding sites. J. Pharmac. exp. Ther. 233, $254-263$.

20. Greenamyre J. T., Penney J. B., Young A. B., Hudson C. Silverstein F. S. and Johnston M. V. (1987) Evidence for transient perinatal glutamatergic innervation of globus pallidus. $J$. Neurnsci. $7,1022-1030$.

21. Hasting M. H. Winn P. and Dunnett S. B. (1985) Neurotoxic amino acid lesions of the lateral hypothalamus: a parametric comparison of the effects of ibotenate, $N$-methyl-D-L-aspartate and quisqualate in the rat. Brain Res. 360 , $248-256$.

22. Johnson J. W. and Ascher P. (1987) Glycine potentiates the NMDA response in cultured mouse brain neurons. Nature 325, 529-531.

23. Kemp J. A., Priestly T. and Woodruff G. N. (1986) MK-801, a novel, orally active anticonvulsant is a potent. non-competitive $N$-methyl-D-aspartate receptor antagonist. Br. J. Pharmac. Proc. (Suppl.) 89, 535P.

24. Lehmann J. and Scatton B. (1982) Characterization of excitatory amino acid receptor-mediated release of [ $\left.{ }^{3} \mathrm{H}\right]$ acetylcholine from rat striatal slices. Brain Res. 252, 77-89.

25. Luini A., Goldberg O. and Teichberg U. 1. (1981) Distinet pharmacological properties of excitatory amino acid receptors in the rat striatum: study by $\mathrm{Na}^{+}$effux assay. Proc. natn. Acad. Sci. U.S.A. 78, 3250-3254.

26. MacDermott A. B., Mayer M. L., Westbrook G. L., Smith S. J. and Barker J. L. (1986) NMDA-receptor activation increases cytoplasmic caicium concentration in cultured spinal cord neurons. Nature 321, 519-522.

27. MacDonald J. F., Porietis A. V. and Wojtowicz J. M. (1982) L-Glutamic acid induces a region of negative slope conductance in the current voltage relationship of cultured spinal cord neurons. Brain Res. 237, 248-253.

28. Maragos W. F., Chu D. C. M., Greenamyre J. T., Penney J. B. and Young A. B. (1986) High correlation between the localization of $\left.{ }^{3} \mathrm{H}\right] \mathrm{TCP}$ binding and NMDA receptors. Eur. J. Pharmac. 123, 173-174.

29. Martin D. and Lodge D. (1985) Ketamine acts as a non-competitive $N$-methyl-D-aspartate antagonist on frog spinal cord in vitro. Neuropharmacology 24, 999-1003.

30. Mayer M. L., Westbrook G. L. and Guthrie P. B. (1984) Voltage-dependent block by $\mathrm{Mg}^{2+}$ of NMDA responses in spinal cord neurons. Nature 309, 261-263.

31. McDonald J. W., Silverstein F. S. and Johnston M. V. (1987) MK-801 protects the neonatal brain from hypoxicischemic damage. Eur. J. Pharmac. 140, 359-361.

32. McDonald J. W., Silverstein F. S., Cardona D., Uckele J., Chen R. and Johnston M. V. (1988) Neuroprotective effects of MK-801 and other compounds on perinatal hypoxic-ischemic injury. In Sigma and PCP Like Compounds as Molecular Probes in Biology (eds Domino E. F. and Kamenka J.-M.), pp. 697-707. NPP Press, Ann Arbor, MI.

33. McDonald J. W. Silverstein F. S. and Johnston M. V. (1988) Neurotoxicity of $N$-methyl-Duaspartate is markedly enhanced in developing rat central nervous system. Brain Res. 459, 200-203.

34. McDonald J. W. Silverstein F. S. and Johnson M. V. (1989) Neuroprotective effects of MK-801, TCP, PCP and CPP against $N$-methyl-D-aspartate induced neurotoxicity in an in piro perinatal rat model. Brain Res. 490, 33-40.

35. Mclennan H. (1981) On the nature of the receptors for various excitatory amino acids in the mammalian central nervous system. Adr. Biochem. Psychopharmac. 27, 253-262. 
36. Meldrum B. (1985) Possible therapeutic implications of antagonists of excitatory amino acid neurotransmitters. Clin. Sci. 68, 113-122.

37. Monaghan D. T., Holets V. R., Toy D. W. and Cotman C. W. (1983) Anatomical distributions of four pharmacolog* ically distinct ${ }^{3} \mathrm{H}$-L-glutamate binding sites. Nature 306, 176-179.

38. Murphy S. N., Thayer S. A. and Miller R. J. (1987) The effects of excitatory amino acids on intracellular calcium in single mouse striatal neurons in vitro. $J$. Neurosci, 7, 357-368,

39. Nadler J. V., Perry B. W. and Cotman C. W. (1978) Intraventricular kainic acid preferentially destroys hippocampal pyramidal cells. Nature 271, 676-677.

40. Nowak L., Bregestovski P., Ascher P., Herbet A. and Prochiants A. (1984) Magnesium gates glutamate-activated channels in mouse central neurons. Nature 307, 462-465.

41. Olney J. W., Ho O. L. and Rhee V. (1971) Cytotoxic effects of acid and sulf containing amino acids on the infant mouse central nervous system. Expl Brain Res. 14, 61-76.

42. Olney J. W., Rhee V. and Ho O. L. (1974) Kainic acid: a powerful neurotoxic analogue of glutamate. Brain Res. 77 , $507-512$.

43. Peters $S$., Koh J. and Choi D. W. (1987) Zinc selectively blocks the action of $N$-methyl-D-aspartate on cortical neurons. Science 236, 589-593.

44. Robinson M. B. and Coyle J. T. (1987) Glutamate and related acidic excitatory neurotransmitters from basic science to clinical application. FASEB. J. 1, 446-455.

45. Rothman S. (1984) Synaptic release of excitatory amino acid neurotransmitter mediates anoxic neuronal death. J. Neurosci. 4, $1884-1891$.

46. Silverstein F. S., Chen R. C. and Johnston M. V. (1986) The glutamate agonist quisqualic acid is neurotoxic in striatum and hippocampus of immature rat brain. Neurosci. Lett. 71, $13-18$.

47. Simon R. P., Swan J. H., Griffiths T, and Meldrum B. S. (1984) Blockade of $N$-methyl-D-aspartate receptors may protect against ischemic damage in the brain. Science 226, 850-852.

48. Sloviter R. S. (1983) "Epileptic" brain damage in rats induced by sustained electrical stimulation of the perforant path. 1. Acute electrophysiological and light microscopic studies. Brain Res. Bull. 10, 675-697.

49. Steiner H. X., McBean G. J., Kohler C., Roberts P. J. and Schwarcz R. (1984) Ibotenate-induced neuronal degeneration in immature rat brain. Brain Res. 307, 117-124.

50. Stewart G. R., Price M., Olney J., Hartman B. K. and Cozzari C. (1986) N-Methylaspartate: an effective tool for lesioning basal forebrain cholinergic neurons of the rat. Brain Res. 369, 377-382.

51. Tsumoto T., Hagihard K., Sato H. and Hata Y. (1987) NMDA receptors in the visual cortex of young kittens are more effective than those of adult cats. Nature 327, 513-514.

52. Watkins J. C. and Evans R. H. (1981) Excitatory amino acid neurotransmitters. A. Rev. Pharmac. Toxicol. 21, $165-204$.

53. Wieloch T. (1985) Hypoglycemia-induced neuronal damage prevented by an $N$-methyl-D-aspartate antagonist. Science 230, 681-683.

54. Wong E. H. F., Kemp J. A.. Priestly T., Knight A. R., Woodruff F. N. and Iversen L. L. (1986) The anticonvulsant MK-801 is a potent $N$-methyl-D-aspartate antagonist. Proc. natn. Acad. Sci. U.S.A. 83, 7104-7108.

55. Zaczek R. and Coyle J. T. (1982) Excitatory amino acid analogues: neurotoxicity and seizures. Neuropharmacology $21,15-26$. 